\title{
Research on Multimodal Metaphor in Mountain May Depart Under the Cross-cultural Context
}

\author{
Yadong Zhu ${ }^{1}$ \\ ${ }^{1}$ College of Humanities, Sichuan Agricultural University, Ya'an, Sichuan, China
}

Keywords: Multimodal Metaphor, Cross-cultural Context, Mountain May Depart.

\begin{abstract}
Research on multimodal metaphor breaks the limitation of traditional research on language, extends to multimodal symbols like images, sound and music, and enhances people's understandings on features and mechanism of metaphor. Since multimodal metaphors are quite common in films, this study discusses and analyzes them in a Chinese film Mountain May Depart to explore how multimodal metaphors are formed to express the theme and gain people's understandings and acceptance from different cultures better under the cross-cultural context.
\end{abstract}

\section{Introduction}

Now multimodality is developing rapidly under the context of globalization and informatization. The concept of multimodal metaphor offered a new way for researches on features and mechanism of metaphor. As an important channel of cross-cultural communication, films are worthy of multimodal study because multimodal metaphors are quite common in films. From the $21^{\text {st }}$ century, the Chinese film industry gets a fast development because of a large market and great potential in development. With examples from a Chinese film Mountain May Depart, this study focuses on how film discourse builds metaphors through multimodal symbols to better express filmmakers' intentions and gain people's understandings and acceptance in cross-cultural communication.

\section{Brief introduction on multimodal metaphors and cross-cultural context}

Existing widely in our lives, metaphor is both rhetorical device and mode of thinking for human beings. According to Lakeoff \&Johnson(1980), people often utilize things that they are familiar with to understand a new thing, and conceptual metaphors form meanings from source domain that are more basic to target domain that are more abstract[1]. It has led to the flourishing researches on metaphor. With the deepening researches and the tendency of multimodality, Charles Forceville(2009) proposed a new concept of multimodal metaphor. It forms meanings from source domain to target domain through two or above two modals, which include pictorial image, written image, oral image, sound, music, smell, contact and so on[2]. Indeed, such a concept breaks the limitation of traditional research on metaphor, opens up a new way for researches of metaphor and enhances people's understandings on features and mechanism of metaphors in modern society. Now many scholars like Koller(2009), Bateman\&Schmidt(2012), utilize it into researches on advertising, cartoon, films and foreign language teaching and deepen our understandings on features and mechanism of metaphors[3],[4].

Cross-cultural communication is becoming an inevitable tendency in such a globalized world even if there are different cultural patterns which display different manners, customs, values and ways of act among different countries. Successful or smooth cross-cultural communication can only be guaranteed on the basis of proper understandings and acceptance towards different cultures, and the final goal of cross-cultural communication is to enhance mutual understandings among different cultures. Such a tendency decides that we can only take the perspective of cross-cultural context to look at one thing or one research, and then it can increase our understandings and broaden our horizon. Since multimodal metaphors form meanings through different modals and demand people 
using various sense to understand, they show dynamic in narration, staggered feature in space and vividness in description[5]. Thus, they are frequently used in different media in cross-cultural communication, like advertising, cartoon, films. Indeed, cross-cultural context can't be ignored in researches of multimodal metaphors and it can enhance a better understanding on multimodality and culture.

\section{Analysis on multimodal metaphors in Mountain May Depart under the cross-cultural context}

Multimodal metaphors in Mountain May Depart. Mountain May Depart is a Chinese film released in 2015 and won many nominations and awards in international film festivals. It presents people's destiny with social changes in China by telling the heroine's life story of 26 years from 1999 to 2025. Kress\&van Leeuwen mentioned that meanings are formed through different modals and expressed in a process of communication[6]. Similarly, multimodal metaphors are formed in films and expressed in a process of communication between filmmakers and audience. Here some shots from this film are chosen to illustrate how multimodal metaphors in films are formed to express filmmakers' intentions and arise the audience' resonance to gain understandings and acceptance.

Firstly, dance is time. As a performing art with music and movement, dance stands for energy. The first shot about dance is that the young heroine acts as a lead dancer and dances happily with a group of young people. Here visual and auditory modals cooperate with each other and display energetic youth. At the end of film, the old heroine walks silently with a dog on the snowfield at dusk and dances slowly with the rhythm in her mind. Here a picture, music and heroine's movement show the oldness and loneliness completely. From these two shots, visual and auditory modals compare with each other and transmit the lonely and desolate destiny of heroine with the change of time and society to the audience. Then the metaphor that dance is time is taken shape.

Secondly, native dialect is homesickness. There exists various dialects in China and those dialects can make people from the same place feel closer to each other. One unique feature is the use of native dialect, fenyang dialect in the whole movie. When it turns to Australia in 2025, the hero Jinsheng chats with some old guys about the past in fenyang dialect, but his son can only speak English fluently and their communication van only depends on software of computer. The different languages they use and their special communicative way give a deep impression on audience. Here multimodal symbols like language, pictures and music all build a connection between native dialect and the homesickness through mapping and meaning's integration. Then the audience are likely to feel those characters' affection and longing for homeland.

Third, keys are friendship and family affection. Indeed, keys are quite common in our daily life. After hearing the heroine Shentao will marry with Jinsheng, another hero Liangzi throws his keys angrily and leave home. When he comes back because of serious illness, the heroine visits him and returns those keys to him. On the shot, the silent hero, brief words from the heroine, the close-up of keys and background music all combine and build a connection between keys and friendship. Another shot about keys happens between the heroine and her son on the train. While the mother and the son are listening to the same song together on the train, she gives keys solemnly to her son who will move to Australia with his father, tells him that he can come back at any time with the keys, and then they lean against each other with the sad melody of music. Here multimodal symbols, such as the music, the short conversation between the mother and the son, the whole picture, all coordinate with each other and express the deep affection between them and unwillingness to be apart vividly. Then the connection is built between keys and family affection and a new metaphor is formed.

Analysis on multimodal metaphors in Mountain May Depart under the cross-cultural context. According to Forceville\&Urios-Aparisi(2009), in the formation of multimodal metaphors, every modal observes specific rules in organizing and coordinating to express meanings[7]. From 
the above description, it is easy to find that visual and auditory modals are mainly adopted to form multimodal metaphors in films, which is closely related to narrative features and technique of films.

In fact, multimodal metaphors in films can be roughly divided into two kinds. One is involved with events. That means, the connection between source domain and target domain is built with coordination of different multimodal symbols through the description of an event. For example, the description from dance at the heroine's youth to dance at her old age builds the connection between dance and time through the utilization of music, sound, language and movement. It can make the theme of film prominent and help people from different cultures understand what the filmmakers want to express easily. The other is involved with objects. Different symbols are often used to create a connection between common objects and other objects with abstract meanings and form a new metaphor to express emotion and intentions better in films. Take Mountain May Depart as an example, dance, native dialects, keys are all common things that can easily arouse people's similar experience in life. With the help of multimodal symbols like pictures, music, language and movement, those common things can be mapped and integrated with other things to build new metaphors and express the theme of films better.

Although the formation of multimodal metaphors can be divided into the above two types, the two kinds of formation can be separated from each other. Sometimes filmmakers combine them through multimodal metaphors to fulfill construction of new metaphors. For instance, to build the connection between keys and family affection, filmmakers use the common keys and describe the whole event of the heroine and her son taking a train to Shanghai through various multimodal symbols. Then the audience can easily construct a new metaphor that keys are family affection. In fact, it can also reflect the dynamic and complex feature of multimodal metaphors in films.

Under the cross-cultural context, films can display cultures of a country or a nation through various forms of art, and it is characteristic of expressing different cultures by using direct and borderless languages[8]. In Mountain May Depart, many things with Chinese feature like Fenyang dialect, Shantou dancing, dumplings are shown to the audience through different forms of art, which is helpful to express Chinese culture to the world. Since the target audience are not limited to Chinese people, while displaying and expressing Chinese culture, the film also utilizes things common in life to create related metaphors to enhance people's understanding and smooth cross-cultural communication. Those common things usually have similar associations or recognition in different cultures, so multimodal metaphors based on them can easily arouse emotional resonate and get understandings and acceptance from people with other cultural backgrounds. Thus, we can see that smooth cross-cultural communication is also an important factor that should be considered in the process of forming multimodal metaphors to express the theme of films.

\section{Conclusion}

In fact, films combine various forms of art and modals and play an important role in cross-cultural communication. Mountain May Depart builds new metaphors by different ways and multimodal symbols to describe and sigh with people's destiny under social changes. Based on the above analysis, we can see the dynamic and complex feature of multimodal metaphor in the special discourse of films, especially the formation of multimodal metaphor. Meanwhile, the formation of those metaphors in films is also related to the requirement under the cross-cultural context. For smooth cross-cultural communication, metaphors are built from the similar objects or phenomena to abstract objects or emotions through different modal symbols so as to get better understandings and acceptance among people from different cultures and express the theme of films better. 


\section{References}

[1] Lakoff, G.\&Johnson, M. Metaphors We Live By[M]. Chicago: University of Chicago Press, 1980.

[2] Forceville, C. Non-verbal and Multimodal Metaphor in a Cognitive Framework: Agendas for research[A]. In C. Forceville \& E. Urios-Aparisi(eds.). Multimodal Metaphor - Applications of Cognitive Linguistics[C]. New York: Mouton de Gruyler, 2009.

[3] Koller,V. Brand images: Multimodal metaphor in corporate branding messages[C]. Forceville\& E. Urios-Aparisi, Multimodal Metaphor, Berlin/New York: Mouton de Gruyter, 2009:45-71

[4] Bateman, J. A \&K.H. Schmidt. Multimodal Film Analysis. London: Routledge, 2012

[5] Zhao Xiufeng, New Development of Conceptual Metaphor Studies: Multimodal Metaphor[J]. Foreign Languages Research, 2011(1):1-10.

[6] Kress, G\&T. van Leeuwen. Multimodal Discourse: The Modes on Media of Contemporary Communication[M]. London, New York: Arnold; Oxford University Press, 2001.

[7] Forceville\&Urios-Aparis, Multimodal Metaphor —Applications of Cognitive Linguistics[C]. New York: Mouton de Gruyler, 2009.

[8] Chen Xiaowei, Dimensionality, Current Situation and Methods on Research of Chinese Films' Cross-cultural Communication[J]. Journal of Zhengzhou University,2014(6):172-176 